\title{
El Principio de Igualdad y No Discriminación. Claroscuros de la Jurisprudencia Interamericana*
}

Este artículo se encuentra disponible en www.anuariocdh.uchile.cl

\author{
Ariel E. Dulitzky**
}

\begin{abstract}
En la Conferencia Regional Preparatoria para la "Conferencia Mundial contra la Discriminación Racial, el Racismo, la Xenofobia y las Formas Conexas de Intolerancia", los Gobiernos de las Américas establecieron principios que dan un marco conceptual para avanzar en la lucha contra la exclusión social y la discriminación en nuestro hemisferio. Reconocieron el carácter multirracial, pluriétnico, multicultural y multilingüístico de las Américas; sostuvieron que el racismo, la discriminación racial, la xenofobia y las formas conexas de intolerancia agravan la condición de pobreza, marginalidad y exclusión social de personas, grupos y comunidades; reafirmaron el deber de la región de proteger y promover las libertades fundamentales de los pueblos indígenas, los pueblos de ascendencia africana, los migrantes, las mujeres y las personas pertenecientes a otros grupos en situación de particular riesgo y concluyeron que el desarrollo democrático y el fomento del Estado de Derecho constituyen premisas fundamentales para erradicar la discriminación racial y la exclusión ${ }^{1}$.
\end{abstract}

Estas premisas son cruciales en América Latina, que es la región más desigual en el mundo desde el punto de vista de la distribución de riqueza ${ }^{2}$. La discriminación de hecho y de derecho continúa afectando a pueblos indígenas, afrodescendientes, mujeres y trabajadores migrantes, entre otros. Muchos de estos grupos son víctimas de violencia, de manera desproporcionada en comparación con el resto de la población, tanto por parte de los agentes de seguridad pública como de actores privados. De modo que el análisis jurídico y la interpretación de las cláusulas de igualdad y no discriminación que se encuentran incluidas en los artículos 1 y 24 de la Convención Americana sobre Derechos Humanos no es un mero ejercicio académico, sino una imperiosa necesidad política y moral para avanzar en la creación de sociedades más equitativas y democráticas.

El principio de igualdad y no discriminación no ha generado mucha jurisprudencia por la Corte y la Comisión Interamericanas de Derechos Humanos. Sin embargo, no por ello se pueden pasar por alto las importantes contribuciones que ambos órganos han realizado, ni algunas de las discusiones teóricas que ellas generan. De las múltiples aristas de análisis alrededor del principio de igualdad y no discriminación en la jurisprudencia interamericana, nos detendremos en dos temas que no

\footnotetext{
* A Cecilia Medina y José Zalaquett, maestros y ejemplos.

** Secretario Ejecutivo Adjunto de la Comisión Interamericana de Derechos Humanos. Las opiniones expresadas en el presente artículo son de la exclusiva responsabilidad del autor y no representan necesariamente los puntos de vista de la Comisión Interamericana de Derechos Humanos, los de su Secretaría Ejecutiva, los de la Secretaría General de la Organización de los Estados Americanos, o los de los Estados Miembros de la OEA. Agradezco los comentarios de Elizabeth Abi-Mershed, Rosa Celorio, Manuela Cuvi y Daniela Salazar.

1 Declaración Final de la Conferencia Regional de las Américas, WCR/RCONF/SANT/20001L. 1/Rev.3, 20 de diciembre de 2000, preámbulo, párrafos declarativos 9 y 11, declaración párrafos 5 y 82, entre otros.

2 Ver Comisión Económica para América Latina y el Caribe (CEPAL), Panorama Social de América Latina, 2000-2001, págs. 17 y sigs. y 67 y sigs.
} 
han sido suficientemente estudiados. Analizaremos los motivos prohibidos de discriminación contenidos en la Convención Americana y en la interpretación que de ellos se ha hecho. Una vez determinada la existencia de un listado de criterios prohibidos de discriminación, analizaremos cuál es el estándar que la Corte y la Comisión utilizan o deberían utilizar frente a las distinciones basadas en ellos. En particular, exploraremos si el estándar debe ser más estricto que el aplicado frente a otras distinciones no expresamente prohibidas por el texto convencional.

El segundo tema que el artículo examinará es el desarrollo jurisprudencial de los órganos interamericanos frente a la relación existente entre violencia y discriminación. En particular si en casos de violencia basada en motivos u orígenes discriminatorios, o en la pertenencia de una persona a un grupo tradicionalmente discriminado, la obligación genérica de investigar, juzgar y sancionar, tan explorada por la Comisión y la Corte, es similar a otros supuestos de violaciones a los derechos humanos o, por el contrario, requiere un énfasis especial fundado en dichas particularidades.

\section{Precisión terminológica previa}

Nos referiremos a la jurisprudencia del sistema interamericano para hacer alusión tanto a las sentencias y opiniones consultivas de la Corte, como a las resoluciones de la Comisión (CIDH) en casos individuales y en sus diferentes informes. Con ello, no pretendemos obviar que en sentido estricto sólo la Corte es un tribunal judicial y, por ende, la única que produce jurisprudencia. Mientras que la Comisión, en tanto órgano con múltiples funciones y facultades, cuasijudiciales y de otras características, no dicta propiamente sentencias y, desde esta perspectiva, no establece jurisprudencia.

Sin embargo, nos referimos a la jurisprudencia del sistema interamericano con la expresa intención de resaltar la igual importancia que la Convención le asigna a las decisiones finales de la Corte y de la Comisión. De acuerdo al artículo 33 de dicho instrumento, ambas son competentes para conocer en los asuntos relacionados con el cumplimiento de los compromisos contraídos por los Estados parte. Esto implica que la Comisión y la Corte deben interpretar la Convención incluyendo la determinación del contenido específico de cada uno de sus artículos. Incluso, en relación con peticiones o casos individuales, la Convención establece una vía doble de determinaciones finales por parte del sistema. En efecto, permite una decisión final de la Comisión en virtud del artículo 51 o de la propia Corte en virtud del artículo 61 y concordantes. Así, la Convención crea dos categorías de casos con dos posibles tipos de decisiones finales. Por lo tanto, el valor de la interpretación de ambos órganos debe ser considerado con igual importancia, lo que no significa que tengan la misma naturaleza jurídica o valor legal ${ }^{3}$.

Así, tanto la Comisión como la Corte están facultadas para precisar los alcances del principio de igualdad y no discriminación. Por estas razones, analizaremos de manera conjunta las decisiones de la Comisión y de la Corte que sean relevantes en materia de igualdad y no discriminación.

\section{Los motivos prohibidos de discriminación y los estándares de revisión}

La Convención Americana contiene un catálogo de criterios específicos en virtud de los cuales está prohibido discriminar. Su artículo 1.1 menciona los siguientes criterios prohibidos de discri-

\footnotetext{
De hecho, tanto la Comisión como la Corte producen decisiones finales de distinto valor jurídico. Así, cabe distinguir en el caso de la Corte entre sentencias en casos contenciosos y opiniones consultivas. En el supuesto de la Comisión, se pueden distinguir sus opiniones en casos individuales en los términos del artículo 51 de la Convención, sus Informes temáticos o sus Informes sobre países.
} 
minación: raza, color, sexo, idioma, religión, opiniones políticas o de cualquier otra índole, origen nacional o social, posición económica, nacimiento o cualquier otra condición social.

De modo que, siguiendo las pautas tradicionales de interpretación de cualquier tratado internacional $^{4}$, el texto convencional como principal punto de partida para analizar cuáles situaciones constituyen alguna forma de discriminación, presenta un listado claro de categorías prohibidas y todos los destinatarios de las normas de derechos humanos saben a qué criterios pueden o no acudir a fin de establecer diferencias. Así, ante una situación que se plantea como discriminatoria, en primer lugar, debe observarse si la cláusula, práctica, norma, acción u omisión estatal que se analiza establece directa o indirectamente diferenciaciones o distinciones basadas en algunas de las categorías vedadas por la Convención.

En la Opinión Consultiva sobre la Condición Jurídica de los Trabajadores Migrantes, que constituye el análisis más elaborado de la Corte Interamericana en materia de discriminación, se indicó que no son admisibles los tratos discriminatorios en perjuicio de ninguna persona por motivos de género, raza, color, idioma, religión o convicción, opinión política o de otra índole, origen nacional, étnico o social, nacionalidad, edad, situación económica, patrimonio, estado civil, nacimiento o cualquier otra condición ${ }^{5}$.

En esta descripción, la Corte incluyó nuevas categorías prohibidas de discriminación (convicción, origen étnico, nacionalidad, edad, patrimonio o estado civil), sin explicar por qué ellas cualifican como alguna "condición social" en los términos del punto final de los artículos 1.1 de la Convención y 26 del Pacto Internacional de Derechos Civiles y Políticos, tratados que estaba llamada a interpretar, o por qué es legítimo incluir nuevos motivos dentro del catálogo existente. En las nuevas categorías incluidas se verifican razones de diferente lógica y entidad. Por lo general, se considera que los factores prohibidos de discriminación tienden a hacer referencia a motivos inmutables o inmodificables por la propia voluntad de la persona (tales como el color o la raza) o bien a factores históricos asociados con prácticas discriminatorias de antigua data (por ejemplo, la religión o el origen nacional). Sin embargo, en la ampliación del catálogo de la Corte es difícil encontrar alguna explicación. Así, mientras el origen étnico es inmutable, el patrimonio no lo es. Mientras la edad no puede modificarse por la propia voluntad de la persona, la nacionalidad en principio sí podría serlo. En tanto algunas de las nuevas categorías incluidas por la Corte han estado asociadas a discriminaciones históricas, por ejemplo el origen étnico, otras no están vinculadas a esta discriminación tradicional, tal como el estado civil. Lamentablemente, se desconocen los criterios utilizados por la Corte para aumentar la nómina de prohibiciones.

El tribunal modificó motivos prohibidos de discriminación, nuevamente sin fundamentar las razones. Hizo referencia a "género" en lugar de "sexo", "situación económica" en lugar de "posición económica", "opinión política" en lugar de "opiniones políticas". Si bien en principio parecería que los cambios referidos a posición económica y opinión política podrían ser simplemente producto del descuido o de la falta de implicación jurídica específica, el cambio de género por sexo tiene consecuencias definidas. En efecto, y simplificando las discusiones sobre sus definiciones, mientras que por género suele entenderse la construcción social de los aspectos psicológicos, sociales y culturales de la feminidad-masculinidad, por sexo se entienden específicamente los componentes biológicos y anatómicos ${ }^{6}$. Precisamente por este motivo se utiliza el término género

4 Artículo 31 de la Convención de Viena sobre Derecho de los Tratados.

5 Corte IDH, Condición Jurídica y Derechos de los Migrantes Indocumentados, Opinión Consultiva OC-18/03, 17 de septiembre de 2003, Serie A No 18, párr. 101 (en adelante OC-18).

6 Ver entre otras, Valerie Oosterveld, The Definition of "Gender" in the Rome Statute of the International Criminal Court: A Step Forward or Back for International Criminal Justice?, 18 Harvard Human Rights Journal 56 (donde se citan las múltiples definiciones de género -y sus implicaciones- utilizadas en el ámbito de las Naciones Unidas). 
para hacer referencia a discriminaciones asociadas a estereotipos y prejuicios culturales y sociales vinculados a lo femenino y lo masculino, y el término sexo para referirse a discriminaciones motivadas exclusiva o predominantemente en factores biológicos o anatómicos. Por ello no puede considerarse que son sinónimos, ni entenderse que género reemplaza a sexo como categoría prohibida de discriminación ${ }^{7}$. Frente a una norma específica de la Convención que habla de sexo, cambiarla sin explicación alguna por género provoca dudas sobre los criterios que utiliza la Corte para apartarse del texto convencional y sobre la legitimidad de hacerlo.

Por último, la Corte en la citada enumeración eliminó dos palabras cruciales al momento de interpretar el carácter cerrado o abierto del listado de criterios prohibidos de discriminación. No incluyó la palabra "cualquier" al referirse a la opinión de [cualquier] otra índole. Pero lo que es más importante, suprimió la palabra "social" al final de la expresión "o cualquier otra condición". Con ello parecería que es posible ampliar el catálogo de prohibiciones, ya que no es necesario que se trate de una condición social sino de una simple condición. Si bien en abstracto la distinción parecería ser suficientemente sutil, en la práctica no lo es. La calificación de "condición social" implica que ella se da en un contexto social determinado, es una construcción social específica u opera en función de las relaciones entre personas, grupos de personas o la sociedad en su conjunto. En cambio, cualquier otra condición, aislada del calificativo "social", amplía enormemente las posibilidades ${ }^{8}$.

La Corte podría haber dado razones para cambiar el listado expreso de prohibiciones contenido en los tratados de derechos humanos interpretados. Podría haber considerado que la interpretación de un instrumento internacional de protección debe "acompañar la evolución de los tiempos y las condiciones de vida actuales ${ }^{\prime \prime}$ y que los tiempos y condiciones presentes exigían estas modificaciones al listado primigenio de la Convención y el Pacto. O que el objeto y fin de estos tratados apuntan al reconocimiento de la dignidad humana y a la necesidad de proteger a las personas asegurando sus derechos fundamentales, y que en razón de ello se requería expandir o modificar el listado expreso de prohibiciones. O que al interpretar a la Convención no sólo se toman en cuenta los acuerdos e instrumentos formalmente relacionados con ellos, sino también el sistema dentro del cual se inscriben ${ }^{10}$. Así, a partir de que otros instrumentos incluyeron nuevas categorías prohibidas de discriminación, podría haberse justificado la legítima expansión del catálogo original para reflejar el consenso internacional actual. Particularmente, en la Opinión Consultiva analizada, la Corte podría haberse servido de la Convención Internacional sobre la Protección de los Derechos de Todos los Trabajadores Migratorios y de sus Familiares, que constituye uno de los instrumentos que amplía el mencionado catálogo ${ }^{11}$.

7 Ver Alda Facio, Engendrando nuestras perspectivas, Otras Miradas, Vol. 2 № 2, diciembre de 2002, pág. 60. Sostiene la autora: "estos términos no se deben usar indiscriminadamente o, peor aún, usar el término género en sustitución de sexo... El género e[n] definitiva, no es un término que viene a sustituir el vocablo "sexo"....

8 Quizás la Corte se guió por el texto del Pacto Internacional de Derechos Civiles y Políticos que si bien en español menciona "cualquier otra condición social" en los textos en inglés y francés no incluye la palabra social ("other status" "toute autre situation"). O por el texto de la Convención Internacional sobre la Protección de los Derechos de Todos los Trabajadores Migratorios y de sus Familiares (ver nota 11 de este trabajo y texto que la acompaña). Sin embargo, la Convención Americana es consistente en los cuatro idiomas oficiales de la OEA ("any other social condition", "toute autre condition sociale", "qualquer outra condição social").

9 Corte IDH, Caso Villagrán Morales y otros (Caso de los "Niños de la Calle"), Sentencia del 19 de noviembre de 1999 , párr. 193. Corte IDH, El Derecho a la Información sobre la Asistencia Consular en el marco de las Garantías del Debido Proceso Penal, Opinión Consultiva OC-16/99, párr. 114.

10 Corte IDH, Opinión Consultiva OC-16/99, párr. 113.

11 En efecto, el artículo 1 de la "Convención Internacional sobre la Protección de los Derechos de Todos los Trabajadores Migratorios y de sus Familiares" incluye casi el mismo listado que utilizó la Corte con la excepción de utilizar la palabra 
Pero al dejar huérfana de una explicación a la sentencia se corren graves riesgos. El más importante de ellos es convertir al texto convencional en algo banal y poco relevante, lo cual puede crear la errónea impresión de que las decisiones acerca del alcance de las normas contenidas en la Convención Americana dependen mayormente del arbitrio de la Corte. Este potencial riesgo no puede ser subestimado por un tribunal que se vale principalmente de la legitimidad de sus sólidos razonamientos jurídicos para hacer cumplir sus decisiones y para determinar la actuación de los tribunales nacionales ${ }^{12}$. La Corte debería tratar al texto convencional como punto de partida inexcusable de cualquier interpretación, lo que no significa pretender que el texto consagre todas las respuestas a las cuestiones vinculadas con su significado. Existirá siempre la necesidad de enfrentar aquí, al igual que en otras áreas del derecho, los problemas ordinarios de interpretación del lenguaje: su ambigüedad, vaguedad y oscuridad. En particular, en materia de derechos humanos, se deben tener en cuenta el objeto y fin de la Convención Americana así como la naturaleza evolutiva del tratado. Ello puede requerir que la interpretación del catálogo de factores prohibidos de discriminación evolucione en el tiempo, permitiendo considerar implícita o explícitamente incluidos en el texto convencional otros motivos de discriminación que la sociedad interamericana rechaza actualmente de manera enfática. Pero siempre deben explicitarse las razones y encontrar una base convencional para hacerlo.

De hecho, la propia lectura de los artículos del Pacto y de la Convención otorgaba esta posibilidad interpretativa. En la enumeración de las categorías prohibidas de discriminación se agrega la frase "cualquier otra condición social", que mantiene abierta la posibilidad de encontrar formas de discriminación no contempladas específicamente, pero que de todos modos constituyen una violación al principio de igualdad asimilable a las categorías establecidas ${ }^{13}$. Ni la Comisión ni la Corte ni el Comité de Derechos Humanos aún han definido claramente el alcance del concepto "cualquier otra condición social". Sin embargo, consideramos adecuado restringir el alcance de la prohibición de discriminación, mediante la aplicación del criterio estricto de revisión que desarrollaremos en el párrafo siguiente, a los casos que impliquen motivos explícitamente enumerados en los respectivos artículos y a los que puedan considerarse como "otra condición social" equiparable a ellos. Ello no significa que otras distinciones no podrán ser objeto de revisión por parte de los organismos de supervisión internacional, sino tan sólo que estas distinciones serán sometidas al análisis de revisión de razonabilidad y no al escrutinio estricto que propondremos.

sexo en lugar de género. Ver artículos 1.1 y 7, que mencionan los siguientes motivos: sexo, raza, color, idioma, religión o convicción, opinión política o de otra índole, origen nacional, étnico o social, nacionalidad, edad, situación económica, patrimonio, estado civil, nacimiento o cualquier otra condición. Agradezco a Manuela Cuvi esta observación.

12 Ver, Laurence R. Helfer y Anne-Marie Slaughter, Toward a Theory of Effective Supranational Adjudication, Yale Law Journal, Vol. 107, № 2, noviembre de 1997, pág. 320-321. La obra citada se refiere a la calidad del razonamiento legal como un factor que influye en el cumplimiento estatal y señala que fundamentar las decisiones y explicar sus razones es un prerrequisito para el ejercicio de una autoridad persuasiva antes que coercitiva.

13 Comité de Derechos Humanos, Caso Gueye v. Francia (La nacionalidad adquirida mediante la independencia, a juicio del Comité entra en el ámbito de la expresión "cualquier otra condición social" que figura en la segunda oración del artículo 26), Comunicación N 196/1985. A/44/40 (1989), párrafo 9.4 y Caso B. v. los Países Bajos (“... [e]l Comité también recuerda que el artículo 26 en su segunda oración establece '... otra condición social'. El Comité advierte que los autores no han aducido que su trato diferente se atribuya al hecho de pertenecer a alguna categoría específica e identificable que les significara encontrarse expuestos a un trato discriminatorio a causa de alguno de los motivos enumerados u 'otra condición social' establecido en el artículo 26..."), Comunicación № 273/1989. A/44/40 (1989), párrafo 6.7. Esta doctrina ha sido criticada por diversas autoras, ver Anne F. Bayefsky, The Principle of Equality or NonDiscrimination in International Law, Human Rights Law Journal, Vol. 11, Nº 1-2, 1990, pág. 6-7, y Patricia Palacios Zuloaga, La No Discriminación, Estudio de la Jurisprudencia del Comité de Derechos Humanos sobre la Cláusula Autónoma de No Discriminación, Centro de Derechos Humanos, Universidad de Chile, 2006, pág. 75. El Comité de Derechos Económicos, Sociales y Culturales consideró que tanto la discapacidad como la edad pueden ser consideradas como "otra condición social" (Ver Observación General № 5, párr. 5 -discapacidad-y Observación General № 6, párr. 11 -edad-). 
A nuestro juicio, la tendencia jurisprudencial está avanzando en el sentido de que las diferencias basadas en los factores prohibidos explícitamente en los instrumentos de derechos humanos, deben estar sujetas a un grado de escrutinio especialmente estricto. Los Estados, a fin de que las distinciones no sean consideradas discriminatorias, deben demostrar la existencia de un interés particularmente importante, de una necesidad social imperiosa, a la par de demostrar que la medida utilizada es la menos restrictiva posible. La Convención, al incluir una referencia expresa de criterios prohibidos de discriminación, representa una explícita interdicción de determinadas diferencias históricamente muy arraigadas que han situado, tanto por la acción de los poderes públicos como por la práctica social, a sectores de la población en posiciones desventajosas y, en muchos casos, contrarias a la dignidad humana. El catálogo convencional representa un reconocimiento expreso de la especial gravedad de las distinciones basadas en tales criterios y un llamado a que los grupos tradicionalmente discriminados con base a ellos reciban una protección especial mediante un estándar de revisión más estricto.

Tradicionalmente, la jurisprudencia proponía evaluar los casos de alegadas discriminaciones analizando si el tratamiento diferenciado perseguía un fin legítimo y si existía una relación razonable de proporcionalidad entre el medio empleado (la diferencia de tratamiento) y el fin perseguido ${ }^{14}$. Sin embargo, en los últimos tiempos ha comenzado a insinuarse un test diferenciado frente a las categorías expresamente mencionadas en el texto convencional. Este test generalmente requiere que el fin de la medida sea legítimo e importante, pero además imperioso. El medio escogido debe ser no sólo adecuado y efectivamente conducente, sino además necesario, es decir, que no pueda ser reemplazado por un medio alternativo menos lesivo. Adicionalmente, el juicio de proporcionalidad exige que los beneficios de adoptar la medida excedan claramente las restricciones impuestas sobre otros principios y valores ${ }^{15}$.

El tratamiento de los motivos incluidos en los catálogos, que algunos denominan "categorías sospechosas" de discriminación, establece que todo trato desigual basado en alguna de esas circunstancias debe ser sometido a un escrutinio especialmente riguroso para evaluar su convencionalidad o constitucionalidad, y a su vez requiere un plus de fundamentación de su objetividad y razonabilidad.

La Comisión ha comenzado a servirse de este criterio estricto de revisión cuando se utiliza el sexo para establecer una distinción en el tratamiento entre hombres y mujeres. Así, la Comisión sostuvo que "se espera un tratamiento equitativo de la ley para hombres y mujeres, a menos que se hayan aducido motivos justos, legítimos y razonables imperiosos para justificar una diferencia de tratamiento"16. Luego, la CIDH introdujo la idea de que "las distinciones previstas en la ley y basadas en criterios relativos a la condición, como, por ejemplo, la raza o el sexo, necesariamente dan lugar a un examen minucioso", en el cual "se tendrían que esgrimir razones de peso para justificar una distinción basada exclusivamente en el sexo"17.

\footnotetext{
14 Ver, Corte Europea de Derechos Humanos, Caso Relating to Certain Aspects of the Laws on the Use of Languages in Education in Belgium (Fondo), 23 de julio de 1968, Volumen 6, Serie A, párr. 10. Este es el primer caso del tribunal que desarrolla esta doctrina.

15 Parafraseando a la Corte Constitucional de Colombia, Sentencia C-673/01, Magistrado ponente Dr. Manuel José Cepeda Espinosa.

$16 \mathrm{CIDH}$, María Eugenia Morales de Sierra v. Guatemala, Caso 11.625, Informe Nº 28/98, párr. 36.

17 Ver CIDH, Consideraciones sobre la compatibilidad de las medidas de acción afirmativa concebidas para promover la participación política de la mujer con los principios de igualdad y no discriminación, en el Informe Anual de la CIDH 1999, OEA/Ser.L/V/II.106, dic. 3 rev., 13 de abril de 2000, capítulo VI, sección II, punto B.
} 
Esta misma formulación fue seguida por la Comisión en el caso "Morales de Sierra"18 relativo a la utilización legislativa del sexo como criterio diferenciador. La CIDH indicó que el artículo 24 de la Convención Americana ha establecido como regla que ciertas formas de diferencia en el trato, como aquellas que se basan en el sexo, resultan "fuertemente sospechosas de ilegalidad," y que el Estado tiene que brindar razones de mucho peso para su justificación. Siempre que la distinción obedezca a algunos de los factores o categorías sospechosas, la norma o la política que la utiliza serán observadas bajo un criterio de escrutinio intenso o estricto ${ }^{19}$.

En su Informe sobre Terrorismo y Derechos Humanos ${ }^{20}$ reiteró que "la doctrina del sistema interamericano de derechos humanos no prohíbe todas las distinciones en el tratamiento del goce de los derechos y libertades protegidas", sino que "requiere en el fondo que toda distinción admisible se funde en una justificación objetiva y razonable, que impulse un objetivo legítimo, habiendo tenido en cuenta los principios que normalmente prevalecen en las sociedades democráticas, y que los medios sean razonables y proporcionados con el fin que se persigue". Pero agregó que "las distinciones basadas en los factores mencionados explícitamente en los instrumentos internacionales sobre derechos humanos están sujetas a un grado de escrutinio especialmente estricto, en virtud de lo cual los Estados deben aportar un interés particularmente importante y una justificación cabal de la distinción" ${ }^{21}$.

Esta tesis fue reafirmada en su reciente Informe sobre Acceso a la Justicia de las Mujeres Víctimas de Violencia. En dicho Informe enfatizó que en la utilización de las categorías sospechosas existe una "presunción del carácter discriminatorio de la medida o política restrictiva". Por ello, cuando se utilizan dichos criterios sospechosos para tratar de manera diferenciada a una persona o grupo, debe realizarse un escrutinio aún mayor para determinar su razonabilidad que cuando se está frente a otro tipo de criterios $^{22}$. Al explayarse, la Comisión vuelve a exigir un análisis de manera concienzuda y pormenorizada de toda restricción fundada en alguna de las categorías del artículo 1.1 de la Convención Americana. Y resumió de esta manera el test al que se someten estas situaciones: "se debe demostrar que dicha restricción está basada en un objetivo estatal imperioso o urgente, que es técnicamente adecuada para lograr ese fin y que éste no puede ser alcanzado por un medio alternativo menos lesivo. Cuando no se pueda acreditar fehacientemente que la restricción cumpla con todos esos requisitos, la misma será inválida porque se asienta exclusivamente en el prejuicio" ${ }^{23}$.

La jurisprudencia europea, a la que asiduamente recurren la Comisión y la Corte, también ha establecido un criterio estricto en ciertas categorías a diferencia del criterio de mera razonabilidad que aplica en la generalidad de los casos de igualdad. Así, la Corte Europea de Derechos Humanos requiere que existan razones de gran importancia para justificar distinciones basadas en ciertas categorías, mientras que en los casos restantes sólo requiere la existencia de un interés legítimo ${ }^{24}$.

$18 \mathrm{CIDH}$, Informe de Fondo No. 4/01, Guatemala, 19 de enero de 2001, párrs. 31 y 36.

19 Ibídem.

$20 \mathrm{CIDH}$, Informe sobre Terrorismo y Derechos Humanos, OEA/Ser.L/V/II.116 Doc. 5 rev. 1 corr, 22 de octubre de 2002.

21 Ibídem, párr. 338.

$22 \mathrm{CIDH}$, Informe sobre Acceso a la Justicia de las Mujeres Víctimas de Violencia, OEA/Ser.L/V/II.Doc. 68, 20 de enero de 2007, párr. 80.

23 Ibídem, párr. 83.

24 Ver Oddny Mjoll Arnardottir, Equality and Non-Discrimination under the European Convention on Human Rights, Martinus Nijhoff Publisher, 2003, págs. 141-155. 
En el caso Adulaziz, Cabales y Balkandakli v. Reino Unido, la Corte Europea declaró que "el desarrollo de la igualdad entre los sexos es, hoy día, un objetivo central de los Estados miembros del Consejo de Europa. Ello significa que deberían presentarse razones de mucho peso antes que una diferencia en el tratamiento con base en el sexo pueda ser considerada compatible con la Convención"25. En Inze v. Austria estableció que: "razones de gran peso habrán de plantearse antes de que pueda considerarse que una distinción en el trato por motivo de nacimiento fuera del matrimonio es compatible con la Convención..."26. En Hoffman v. Austria sostuvo que una distinción basada esencial y solamente en la religión no es aceptable ${ }^{27}$. De manera interesante, en materia de raza, la Corte Europea ha sostenido que debe prestarse una especial importancia a la discriminación basada en ella ${ }^{28}$, pero hasta el momento no ha aplicado en ningún caso un estándar estricto de revisión frente a la alegada discriminación.

La necesidad de que existan razones de una relevancia especial para justificar distinciones basadas en ciertos motivos, clases o categorías, es utilizada también en la jurisprudencia comparada de varios países de la región. Ello puede ayudar a la Comisión y a la Corte a avanzar en esta línea jurisprudencial. Así, en los Estados Unidos, este concepto se desarrolló alrededor de la teoría de la existencia de "categorías sospechosas". En el tristemente famoso caso Korematsu v. United States, la Corte Suprema consideró que: "...todas las restricciones legales que limitan los derechos civiles de un determinado grupo racial son inmediatamente sospechosas. Esto significa que los tribunales las deben someter al escrutinio más estricto. Una urgente necesidad pública puede, a veces, justificar la existencia de tales restricciones; el antagonismo racial, nunca" ${ }^{29}$. Más adelante, agregó en Palmore v. Sidoti que las clasificaciones raciales "están sujetas al escrutinio más exhaustivo y para salvar la exigencia constitucional, deben justificarse en virtud de un interés gubernamental apremiante y deben ser necesarias (...) para la consecución de sus fines legítimos" ${ }^{\prime 30}$. En Loving v. Virginia, la Corte Suprema estipuló que la cláusula sobre igual protección de la Constitución "demanda que las clasificaciones raciales, especialmente en los estatutos penales, deben estar sujetas al escrutinio más riguroso" ${ }^{31}$. Esta teoría, que incluye como categorías sospechosas a la raza y el origen nacional entre otras, exige no sólo una estricta revisión judicial sino que también requiere la demostración de una necesidad pública urgente o necesidad social imperiosa y no un mero interés legítimo.

El Tribunal Supremo de Justicia de Venezuela estableció a) la necesidad de la "probanza plena de la justificación, probadamente necesarísimo y probadamente eficaz para el objetivo importante, necesario e indispensable; b) la necesidad fundamental, cuya realización se hace necesaria de la exigencia de la condición discriminatoria requerida; c) el carácter predictor que tal condición posee para alcanzar ambas necesidades, mediante métodos profesionalmente probados y aceptados; y, d) la imposibilidad de alcanzar los objetivos señalados sin el establecimiento de la condición discriminatoria y la inexistencia de otro medio, vía o condición mediante el cual sería sustancialmente efectivo alcanzar tales objetivos, sin incurrir en la situación discriminatoria prohibida o menos discriminatoria que la derivada de la condición de igual naturaleza alegada" ${ }^{\prime 2}$.

\footnotetext{
25 Corte Europea de Derechos Humanos, Adulaziz, Cabales y Balkandakli v. Reino Unido, 28 de mayo de 1985, párr. 78.

26 Corte Europea de Derechos Humanos, Inze v. Austria, 28 de noviembre de 1987, párr. 41.

27 Corte Europea de Derechos Humanos, Hoffman v. Austria, 23 de junio de 1993, párr. 36.

28 Corte Europea de Derechos Humanos, Cyprus v. Turkey, 10 de mayo de 2001, párr. 306.

29323 US 214. A pesar del estándar utilizado, la Corte Suprema consideró constitucional la reclusión de ciudadanos americanos y latinoamericanos de origen japonés en campos de internamiento durante la Segunda Guerra Mundial.

304666 US 429

31388 US 1, 87.

32 Tribunal Supremo de Venezuela, Sentencia 1024, 3 de mayo de 2000, Magistrado Ponente José Rafael Tinoco.
} 
En el mismo sentido, la Corte Constitucional de Colombia explicó que ha aplicado un test estricto de razonabilidad en ciertos casos, como por ejemplo: 1) cuando está de por medio una clasificación sospechosa como las enumeradas en forma no taxativa a manera de prohibiciones de discriminación en la Constitución; 2) cuando la medida recae principalmente en personas en condiciones de debilidad manifiesta, grupos marginados o discriminados, sectores sin acceso efectivo a la toma de decisiones o minorías insulares y discretas; 3) cuando la medida que hace la diferenciación entre personas o grupos prima facie afecta gravemente el goce de un derecho constitucional fundamental; o 4) cuando se examina una medida que crea un privilegio ${ }^{33}$. Estableció la Corte Constitucional que las categorías señaladas como sospechosas (i) se fundan en rasgos permanentes de las personas, de los cuales éstas no pueden prescindir por voluntad propia a riesgo de perder su identidad; (ii) han estado sometidas, históricamente, a patrones de valoración cultural que tienden a menospreciarlas; y, (iii) no constituyen per se, criterios que permitan efectuar una distribución o reparto racional y equitativo de bienes, derechos o cargas sociales $^{34}$.

La Corte Suprema de Justicia de la Nación argentina también ha seguido esta línea jurisprudencial. En Calvo y Pesini, donde se cuestionaba una ley provincial que impedía el ingreso a planta en los hospitales públicos provinciales a quienes no eran argentinos, la Corte Suprema hizo lugar a la demanda por entender que el Estado no había acreditado una "justificación suficiente de la restricción", considerando insuficiente, en ese caso concreto, "una dogmática afirmación de su postura" 35 . Posteriormente agregaría que una norma que distinguía entre argentinos por nacimiento y naturalizados "se presenta afectada por una presunción de inconstitucionalidad que sólo podría ser remontada por la prueba concluyente de que existe un sustancial interés (...) que la justifique" ${ }^{\prime 36}$. La Corte Suprema se refiere expresamente a "la presencia de un criterio de distinción sospechoso", lo cual hace pesar sobre la norma impugnada una "presunción de inconstitucionalidad" "con desplazamiento de la carga de la prueba"37. Esta presunción de inconstitucionalidad sólo puede ser superada mediante una cuidadosa prueba sobre los fines que se intentaron resguardar y sobre los medios que se utilizaron al efecto. En cuanto a los primeros, deben ser sustanciales y no basta su mera conveniencia. En cuanto a los segundos, será insuficiente una genérica "adecuación a los fines, sino que deberá juzgarse si los promueven efectivamente y, además, si no existen otras alternativas menos restrictivas para los derechos en juego que las impuestas por la regulación cuestionada" ${ }^{38}$.

En resumen, mientras en el criterio de "razonabilidad" se advierte una importante tolerancia respecto de los medios y los fines elegidos por la autoridad que establece las distinciones, en el criterio más estricto existe una presunción de invalidez respecto del objetivo perseguido por el Estado que se funda en una pauta considerada "sospechosa". En consecuencia, el Estado debe presentar fuertes razones ("una necesidad social imperiosa" o "razones de mucho peso") para justificar la utilización de la categoría "sospechosa". En general, rara vez se encuentra que las razones aducidas por el Estado son suficientes, por lo que dichas clasificaciones tienden a ser consideradas contrarias a las normas de derechos humanos, a las constitucionales, o a ambas.

\footnotetext{
33 Corte Constitucional de Colombia, Sentencia C-673/01, Magistrado ponente Dr. Manuel José Cepeda Espinosa.

34 Véase Corte Constitucional de Colombia, Sentencia C-101/05.

35 CSJN, Calvo y Pesini, Rocio c/Córdoba, Provincia de s/Amparo; Fallos 321:194.

36 CSJN, Hooft, Pedro Cornelio Federico c/Buenos Aires, Provincia de s/acción declarativa de inconstitucionalidad, Fallos 322:3034, considerando 2.

37 Ibídem, considerando 5.

38 Ibídem, considerando 6.
} 
El empleo de los motivos incluidos en los catálogos no queda absolutamente vedado, simplemente se establece una presunción de ilegitimidad de la norma, política, o acción basada en tales criterios de distinción. Desde el punto de vista del control convencional, esta presunción de ilegitimidad se traduce en la inversión de la carga justificatoria y en su sometimiento a un estándar de escrutinio elevado. Acreditado el empleo de una clasificación sospechosa, la inversión de la carga justificatoria pone en cabeza del Estado la fundamentación de la medida impugnada. Cabe entonces al Estado demostrar las razones concretas que condujeron a acudir a dicha clasificación para establecer una distinción legal. A falta de demostración suficiente por parte del Estado, la presunción de ilegitimidad queda confirmada y la medida no supera el examen de convencionalidad ${ }^{39} \mathrm{o}$ constitucionalidad. El estándar probatorio que debe cumplir el Estado para justificar la norma es, además, un estándar más elevado que el de mera razonabilidad. Debe probar que el empleo de la clasificación sospechosa es estrictamente necesario para el cumplimiento de un fin socialmente imperioso y debe justificar por qué es necesario acudir a él para cumplir esos fines ${ }^{40}$.

\section{Violencia, discriminación y la debida diligencia en la investigación}

La discriminación y la intolerancia suelen constituir la base de otras violaciones de derechos humanos y ser generadoras de violencia contra grupos tradicionalmente discriminados. Desde el punto de vista normativo, un caso ilustrativo es la Convención Interamericana para Prevenir, Sancionar y Erradicar la Violencia contra la Mujer (en adelante, "Convención de Belém do Pará") , la cual reconoce expresamente la relación que existe entre violencia de género y discriminación, indicando que tal violencia es una manifestación de las relaciones de poder históricamente desiguales entre mujeres y hombres ${ }^{41}$, y que el derecho de las mujeres a una vida libre de violencia incluye el derecho a ser libres de toda forma de discriminación y a ser valoradas y educadas sin patrones estereotipados $^{42}$. El Comité que vigila el cumplimiento de la Convención sobre la Eliminación de Todas las Formas de Discriminación Contra la Mujer ha manifestado que la violencia contra las mujeres es una forma de discriminación que limita el ejercicio de los derechos civiles, políticos, sociales y económicos ${ }^{43}$. Otros ejemplos de esta conexión entre violencia y discriminación son los crímenes de odio (hate crimes) ${ }^{44}$ y, como caso extremo, el crimen internacional de genocidio, que precisamente tiene la intención de destruir, total o parcialmente, a un grupo nacional, étnico, racial, o religioso ${ }^{45}$.

39 Utilizamos el concepto de control de convencionalidad o examen de convencionalidad en el sentido utilizado recientemente por la Corte Interamericana. Ver Corte IDH, Caso Trabajadores Cesados del Congreso (Aguado Alfaro y otros) v. Perú, Sentencia sobre Excepciones Preliminares, Fondo, Reparaciones y Costas, 24 de noviembre de 2006, Serie C N ${ }^{\circ} 158$, párr. 128 ("Ios órganos del Poder Judicial deben ejercer no sólo un control de constitucionalidad, sino también "de convencionalidad" ex officio entre las normas internas y la Convención Americana").

40 Ver mutatis mutandi, Tribunal Superior de la Ciudad de Buenos Aires, Caso Salgado c/ Gobierno de la Ciudad de Buenos Aires, Expte. № 826/01, 21 de noviembre de 2001, voto del Juez Maier, considerando 4.

41 Convencion de Belém do Pará, preámbulo.

42 Convencion de Belém do Pará, artículo 6.

43 CEDAW, Recomendación General 19, "Violencia Contra la Mujer", U.N. Doc. HRI/GEN/1//Rev.1, p. 84, párrs. 1, 6 y 7, 1994.

44 Se puede entender como crimen de odio a la ofensa criminal cometida contra una persona, propiedad o sociedad, motivada en todo o en parte, por el prejuicio racial, religioso, por discapacidad, orientación sexual u origen étnico o nacional. Ver U.S. Department of Justice, Federal Bureau of Investigation (FBI), Hate Crime Data Collection Guidelines, Uniform Crime Reporting, octubre de 1999 (revised), disponible en http://www.fbi.gov/ucr/hatecrime.pdf, pág. 4 (visitado por última vez el 27 de marzo de 2007).

45 Ver artículo II de la Convención para la Prevención y la Sanción del Delito de Genocidio y el artículo 6 del Estatuto de Roma de la Corte Penal Internacional. 
La Comisión se ha mostrado particularmente atenta a la violencia de la que son víctimas personas pertenecientes a grupos tradicionalmente discriminados. En un caso de ejecución extrajudicial de un joven afrodescendiente por parte de la policía, sostuvo que percibía una notable influencia del factor racial. En relación con ello resaltó su preocupación por la violencia contra los jóvenes en Brasil, enfatizando especialmente el nexo existente entre esta relación y los elementos raciales. Y, haciéndose eco de varios estudios, recalcó que la mayoría de las víctimas de la violencia policial en el territorio del Estado son jóvenes pobres, de raza negra o mestiza, muchos de los cuales carecen de antecedentes penales ${ }^{46}$. Sin embargo, en el caso concreto, la Comision consideró que no contaba con suficientes pruebas para establecer que el factor racial haya sido determinante en la ejecución extrajudicial de la víctima.

En el caso de las mujeres, la $\mathrm{CIDH}$ ha establecido que la obligación de garantizar la igualdad y no discriminación está vinculada con la prevención, la investigación y la sanción de la violencia contra ellas. En su Informe sobre la Condición de la Mujer en las Américas ${ }^{47}$ indicó que la falta de igualdad formal de las mujeres las coloca en una situación de desprotección frente a la violencia. Sostuvo que "la mujer aún no alcanza igualdad jurídica plena en todos los países de la región" ya que varios poseen, en mayor o menor medida, normas discriminatorias. Resaltó que "en numerosos códigos penales valores tales como la honra, el pudor social, la doncellez, la castidad, las buenas costumbres, prevalecen sobre valores como la integridad psicofísica y la libertad sexual, impidiendo así la debida protección legal a las víctimas de tales delitos, u obligándolas a probar que pusieron resistencia en el caso del delito de violación, o sometiéndolas a procedimientos interminables que producen una continua victimización". Esto conlleva a situaciones de desprotección hacia las mujeres víctimas de violencia, por falta de legislación adecuada o porque la legislación vigente no se cumple ${ }^{48}$.

La Comisión ha establecido que las actitudes tradicionales, conforme las cuales las mujeres son consideradas subordinadas frente a los hombres o asociadas a funciones estereotipadas, perpetúan prácticas difundidas que conllevan violencia o coerción, como la agresión y el abuso familiares. De esta manera, la violencia contra las mujeres es una forma de discriminación y, por ende, el deber de investigarla y sancionarla adquiere una dimensión especial. En el caso Maria da Penha Fernandes del año 2001, por primera vez, la CIDH estableció frente a una petición individual el vínculo entre la discriminación y la violencia de la que son objeto las mujeres. Este caso, presentado por una víctima de violencia doméstica en Brasil, permitió a la CIDH aplicar la Convención de Belém do Pará por primera vez y decidir que el Estado no había actuado con la debida diligencia para prevenir, sancionar y erradicar la violencia doméstica, al no condenar y sancionar al victimario ${ }^{49}$. Más aún, estableció la existencia de un patrón general de tolerancia estatal e ineficacia judicial hacia casos de violencia doméstica, lo que a criterio de la CIDH constituyó una práctica discriminatoria. La Comisión determinó que la obligación de los Estados de actuar con debida diligencia va más allá que la de procesar y condenar, ya que también incluye la obligación de "prevenir estas prácticas degradantes" ${ }^{50}$. Llama la atención que la Comisión, a pesar de dichas determinaciones y de haber analizado expresamente el derecho a la igualdad ante la ley, no concluyera que en este caso se violó el artículo 24 de la Convención ${ }^{51}$.

46 CIDH, Informe Nº 33/04, Caso 11.634, Jailton Neri Da Fonseca v. Brasil, párrs. 35-38.

$47 \mathrm{CIDH}$, Informe sobre la Condición de la Mujer en las Américas, OEA/Ser.L/V/II.100, Doc. 17, 13 de octubre de 1998.

48 Ibídem.

${ }^{49} \mathrm{CIDH}$, Informe No 54/01 -admisibilidad y fondo-, Caso 12.051, Maria da Penha Maia Fernandes v. Brasil.

50 Ibídem, párr. 56.

51 La CIDH encontró que el Estado había violado los derechos de la víctima a garantías y protecciones judiciales efectivas bajo los artículos 8 y 25 de la Convención Americana, en concordancia con la obligación general de respetar y garantizar estos derechos bajo el artículo 1.1, y el artículo 7 de la Convención de Belém do Pará, ibídem párrs. 45-50 y 60. 
La relación entre violencia y discriminación se ha reflejado además en el informe sobre los homicidios en contra de mujeres en Ciudad Juárez, México. Nuevamente, la CIDH reafirmó que la discriminación basada en el género es un obstáculo en la sanción y prevención de asesinatos de mujeres. Destacó que la violencia y la falta de respuesta ante este tipo de casos obedeció a la discriminación que afecta a las mujeres. Indicó que "no se ha prestado suficiente atención a la necesidad de hacer frente a la discriminación que subyace en los delitos de violencia sexual y doméstica, y que igualmente subyace en la ineficacia en cuanto a la aclaración de los delitos y el procesamiento de los culpables. Para resolver esos casos de homicidio es preciso prestar atención a las causas raigales de la violencia contra la mujer en todas sus principales manifestaciones" 52 .

En el Informe sobre Las Mujeres Frente a la Violencia y la Discriminación Derivadas del Conflicto Armado en Colombia, la Comisión expuso las características de la discriminación y violencia contra las mujeres en el contexto del conflicto armado colombiano, así como las consecuencias de la situación de desventaja y su manipulación y explotación por parte de los actores de dicho conflicto. Muchos de los estándares específicos que se desarrollaron en este informe son similares a los que analizaremos con más detalle al describir el Informe sobre Acceso a la Justicia de las Mujeres Víctimas de Violencia. Pero hay un elemento de este informe que deseamos resaltar. La CIDH indicó que la situación de las mujeres indígenas y afrocolombianas es particularmente crítica al ser víctimas de múltiples formas de discriminación por causa de su raza, etnia y por el hecho de ser mujeres, situación que se agrava dentro del ámbito del conflicto armado ${ }^{53}$. Recordó que la Convención de Belém do Pará establece que al actuar con debida diligencia, el Estado debe tomar especial cuenta de la situación de vulnerabilidad a la violencia que pueden sufrir las mujeres en razón de su raza y etnia, entre otras condiciones de riesgo ${ }^{54}$. Y reconoció que las mujeres indígenas y afrocolombianas todavía confrontan numerosos obstáculos de naturaleza legislativa, institucional, cultural, y geográfica para acceder a una justicia efectiva. Para abordar estas carencias, indicó la necesidad de establecer programas sostenibles de capacitación para operadores de justicia y de entablar iniciativas para sensibilizar a la población y promover el aumento de denuncias ${ }^{55}$.

Indudablemente, el informe donde de manera más detallada se aborda la materia es el recientemente publicado sobre Acceso a la Justicia de las Mujeres Víctimas de Violencia ${ }^{56}$. En dicho informe, la Comisión hizo especial hincapié en el problema de la violencia contra las mujeres como una manifestación de la discriminación basada en el género. Recalcó la obligación de los Estados de organizar su estructura gubernamental para prevenir, investigar, sancionar y reparar actos de violencia contra las mujeres y la discriminación. Enfatizó los principios que deben regir las leyes y políticas públicas, tales como el deber del Estado de erradicar efectiva y prontamente diferentes formas de violencia contra las mujeres, cometida tanto por agentes estatales como no estatales; el de proveer recursos judiciales efectivos e imparciales para víctimas de violencia, y el de implementar acciones para erradicar la discriminación contra las mujeres y los patrones estereotipados de comportamiento que promueven un trato inequitativo en sus sociedades, lo que ha implicado para ellas un acceso desigual a los derechos y a los beneficios derivados de los avances políticos, civiles y sociales.

52 CIDH, Situación de los Derechos de la Mujer en Ciudad Juárez, México: El Derecho a no ser objeto de violencia y discriminación, párr. 11.

$53 \mathrm{CIDH}$, Las Mujeres Frente a la Violencia y la Discriminación Derivadas del Conflicto Armado en Colombia, OEA/Ser. L/V/II., Doc. 67, 18 de octubre de 2006, párr. 102 y sigs.

54 Artículo 9, ibídem, párr. 104.

55 Ibídem, ver entre otros párr. 19.

$56 \mathrm{CIDH}$, Acceso a la Justicia para Mujeres Víctimas de Violencia en las Américas, OEA/Ser.L/V/II., Doc. 68, 20 de enero de 2007. 
La Comisión exploró detenidamente el contenido del artículo 7 de la Convención de Belém do Pará, que impone a los Estados el deber de actuar con debida diligencia frente a la violencia contra las mujeres. Interpretó que la obligación de tomar todas las medidas apropiadas, incluyendo medidas de tipo legislativo, para modificar o abolir leyes y reglamentos vigentes o para modificar prácticas jurídicas o consuetudinarias que respalden la persistencia o la tolerancia de la violencia contra las mujeres, incluye el deber de revisión de normas, prácticas y políticas públicas discriminatorias o cuyo efecto pueda resultar discriminatorio en perjuicio de ellas. Esto debe hacerse "debido a la relación evidente entre discriminación y violencia". Como ejes centrales de esta teoría insistió en que la discriminación se halla en la raíz de la violencia contra las mujeres ${ }^{57}$, que la definición de discriminación contra las mujeres comprende la violencia contra ellas en todas sus formas ${ }^{58}, y$, principalmente, que la discriminación perpetúa esta violencia y, por ello, la Convención de Belém do Pará reconoce un vínculo crítico entre la adecuada protección judicial y su eliminación ${ }^{59}$.

La Comisión hizo un largo y detallado análisis de las obligaciones de investigar, juzgar y sancionar la violencia contra las mujeres de acuerdo a los artículos 8 y 25 de la Convención Americana, a la luz del principio de la debida diligencia contenido en el artículo 7 de la Convención de Belém do Pará. Todo ello, considerando la íntima relación entre la discriminación y la violencia. La Comisión no consideró que la debida diligencia contenida en la Convención de Belém do Pará sea una simple reiteración de las obligaciones que emergen del deber de prevenir, investigar, juzgar, sancionar y reparar de los artículos 1, 8 y 25 de la Convención. Por el contrario, derivó obligaciones concretas, como la de simplificar procedimientos judiciales penales e incrementar el número de instancias para denunciar la violencia contra las mujeres ${ }^{60}$, así como la de producir, compilar, analizar y difundir información sobre sus causas, consecuencias y frecuencia ${ }^{61}$. También la Comisión dio pautas sobre el tipo de pruebas y de valoraciones permisibles en casos de violencia sexual, tales como la obligación de no considerar la falta de resistencia física de la víctima como un factor para no sancionar al agresor ${ }^{62}$. Exigió, dada la íntima correlación entre la discriminación y los parámetros de la debida diligencia en la investigación contenidos en la Convención de Belém do Pará, que tanto los fiscales como los policías eviten cualquier tipo de discriminación en su trabajo y consideren las necesidades especiales de las víctimas de violencia sexual ${ }^{63}$. Y, en este sentido, rechazó la influencia de patrones socioculturales discriminatorios que resulten en una descalificación de la credibilidad de la víctima, a la vez que criticó la interpretación discriminatoria de evidencias en casos de violencia contra las mujeres ${ }^{64}$.

En definitiva, según la interpretación de la Comisión, la investigación de casos donde se interrelaciona violencia y discriminación requiere de un deber de diligencia particular, que analice el hecho mismo de violencia como el factor discriminatorio que pudo haberla motivado, agravado o caracterizado de manera particular.

En un sentido similar, la Corte Europea de Derechos Humanos ${ }^{65}$ ha determinado que los Estados tienen la obligación general de conducir una investigación efectiva en casos de privación de la

\footnotetext{
57 Ibídem, párr. 12.

58 Ibídem, párr. 13.

59 Ibídem, párr. 33.

60 Ibídem, párr. 37.

61 Ibídem, párrs. 42 y sigs.

62 Ibídem, párr. 51.

63 Ibídem, párrs. 52 y 53.

64 Ibídem, párrs. 155 y 157.

65 Caso Nachova y otros v. Bulgaria, Aplicaciones № 43577/98 y Nº 43579/98, ECHR, 6 de julio de 2005. Traducción no oficial.
} 
vida. Esa obligación debe ser cumplida sin discriminación. A su vez, agregó la Corte Europea que donde existan sospechas de que actitudes raciales indujeron a un acto violento, es particularmente importante que una investigación oficial sea llevada a cabo con vigor e imparcialidad, teniendo en cuenta la necesidad de reafirmar continuamente la condena de la sociedad al racismo, y de mantener la confianza de las minorías en la capacidad de las autoridades para protegerlas de la amenaza de la violencia racial. Un cumplimiento del Estado de su obligación positiva requiere que el sistema legal doméstico demuestre su aptitud para aplicar la ley criminal contra aquellos que arbitrariamente quiten la vida de una persona, sin importar el origen étnico o racial de ella ${ }^{66}$.

El tribunal europeo sostuvo que la investigación de incidentes violentos y, en particular, de muertes por manos de agentes del Estado impone a las autoridades el deber adicional de tomar todas las medidas razonables para desenmascarar cualquier motivo racista, y el de establecer si algún odio o prejuicio étnico pudo haber jugado un rol en los eventos. Fracasar en este obrar y tratar la brutalidad inducida por motivos raciales en un pie de igualdad con aquellos casos que no tienen matices racistas, sería volverse ciego a la naturaleza específica de actos que son considerados particularmente destructivos de los derechos fundamentales. No hacer una distinción en situaciones que son esencialmente diferentes puede constituir un tratamiento injusto, irreconciliable con el principio de igualdad. Con el fin de mantener la confianza pública en la maquinaria que pone en ejecución la ley, los Estados parte deben asegurar que en la investigación de incidentes que involucren el uso de la fuerza se distinga, tanto en el sistema legal como en la práctica, entre casos en donde existe un uso excesivo de ella y casos en los que se verifican motivos racistas. Probar la existencia de motivos racistas resulta extremadamente dificultoso. Por ello, el Estado tiene la obligación de investigar todo tinte racista de un acto violento empleando sus mejores esfuerzos ${ }^{67}$.

Lamentablemente, hasta ahora la Corte Interamericana no ha avanzado en esta línea jurisprudencial. En casos donde tuvo la oportunidad de analizar, respectivamente, la correlación entre violencia y origen étnico así como violencia y género, la Corte se limitó a transcribir textualmente su doctrina tradicional sobre las obligaciones del Estado en materia de investigación. Así, no hizo diferencias entre las situaciones generales de violencia y aquellas que presentan componentes y matices discriminatorios, o que se dirigen directamente hacia algunas personas que pertenecen a grupos que tradicionalmente han sido marginados.

En el caso Masacre Plan de Sánchez, la Corte dio por probado que "el Ejército de Guatemala, con fundamento en la "Doctrina de Seguridad Nacional", identificó a los miembros del pueblo indígena maya como "enemigos internos", por considerar que constituían o podían constituir la base social de la guerrilla. Estos pueblos fueron víctimas de masacres y "operaciones de tierra arrasada" que significaron la destrucción completa de sus comunidades, viviendas, ganado, cosechas y otros elementos de supervivencia, su cultura, el uso de sus propios símbolos culturales, sus instituciones sociales, económicas y políticas, sus valores y prácticas culturales y religiosas" ${ }^{68}$. Y agregó que "hechos como los señalados, que afectaron gravemente a los miembros del pueblo maya achí en su identidad y valores y que se desarrollaron dentro de un patrón de masacres, causan un impacto agravado que compromete la responsabilidad internacional del Estado que esta Corte tomará en

\footnotetext{
66 Ibídem.

67 Ibidem.

68 Corte IDH, Caso Masacre Plan de Sánchez v. Guatemala, Sentencia del 29 de abril de 2004, Serie C No 105 , párr. 42.7.
} 
cuenta al momento de resolver sobre reparaciones" ${ }^{69}$. La Corte también había dado por probado que varias mujeres habían sido víctimas de violencia sexual ${ }^{70}$.

Al momento de ordenar las reparaciones correspondientes y a pesar de recordar la gravedad de los hechos que afectaron a los miembros del pueblo maya achí en su identidad y valores, la existencia de un patrón de masacres e impunidad, la intensidad del sufrimiento causado a las víctimas y las alteraciones de sus condiciones de vida, la Corte tan sólo estimó necesario ordenar el pago de una compensación por concepto de daño inmaterial, conforme a equidad ${ }^{71}$. La Comisión había establecido la necesidad de que las medidas inmateriales de reparación, incluida la de investigación, tengan en cuenta "la perspectiva colectiva, fundada en la comprensión de los elementos socioculturales característicos del pueblo maya (...) y la magnitud de los actos genocidas cometidos en su contra". La CIDH sostuvo ante el tribunal "que para los miembros de la comunidad de Plan de Sánchez la justicia es crucial para la reconciliación, la recomposición del tejido social y el proceso de dignificación del pueblo maya, a quienes por factores racistas le ha sido sistemáticamente denegada"72.

No obstante, la Corte al ordenar las investigaciones relativas a la masacre no consideró necesario realizar determinaciones adicionales tales como la exigencia de que la investigación desenmascare cualquier motivo racista, prejuicios étnicos, o una violencia y brutalidad exacerbada por criterios discriminatorios. Apenas sostuvo: "Este Tribunal se ha referido en reiteradas ocasiones al derecho que asiste a los familiares de las víctimas de conocer lo que sucedió y de saber quiénes fueron los agentes del Estado responsables de los respectivos hechos. Tal como ha señalado la Corte, teniendo en cuenta las circunstancias agravantes del presente caso, la investigación de los hechos y la sanción de las personas responsables [...] es una obligación que corresponde al Estado siempre que haya ocurrido una violación de los derechos humanos y esa obligación debe ser cumplida seriamente y no como una mera formalidad"73.

Recientemente, Castro Castro v. Perú se transformó en el primer caso en el que la Corte aplicó la Convención de Belém do Pará74. El tribunal consideró que dicho instrumento constituye una referencia de interpretación de la Convención Americana ${ }^{75}$. Y añadió de manera puntual que de acuerdo a las obligaciones internacionales contraídas por el Perú, éste tiene el deber de garantizar el derecho de acceso a la justicia de acuerdo a lo establecido en la Convención Americana, pero además conforme a las obligaciones específicas que le imponen las Convenciones especializadas que ha suscrito y ratificado en materia de prevención y sanción de la tortura y de la violencia contra las mujeres ${ }^{76}$. De acuerdo al artículo 7. b de dicho tratado, Perú estaba obligado a actuar con la debida diligencia para investigar y sancionar este tipo de violencia ${ }^{77}$. Concluyó la Corte que, a fin de analizar si el Estado había cumplido con la obligación de investigar dispuesta en los artículos 8 y 25 de la Convención Americana, aplicaría las referidas disposiciones de la Convención de Belém do Pará, en razón de que especifican y complementan las obligaciones generales que

\footnotetext{
69 Ibídem, párr. 51.

70 Ibídem, párr. 49.19.

71 Corte IDH, Caso Masacre Plan de Sánchez v. Guatemala, Reparaciones (art. 63.1 Convención Americana sobre Derechos Humanos). Op. cit., párrs. 80 y 82.

72 Ibídem, párr. 90 a y e.

73 Ibídem, párr. 96.

74 Corte IDH, Caso del Penal Miguel Castro Castro v. Perú, Sentencia del 25 de noviembre de 2006, Serie C No 160.

75 Ibídem, párr. 276.

76 Ibídem, párr. 377.

77 Ibídem, párr. 377.
} 
tiene el Estado con respecto al cumplimiento de los derechos consagrados en la Convención Americana ${ }^{78}$. También el tribunal interamericano reconoció que la violencia sexual contra las mujeres tiene consecuencias físicas, emocionales y psicológicas devastadoras para ellas, que se ven agravadas en los casos de mujeres detenidas ${ }^{79}$. No pueden dejar de destacarse estos importantísimos fundamentos, particularmente teniendo en cuenta que la Comision Interamericana en su demanda no había siquiera invocado la Convención de Belém do Pará ni la violencia contra las mujeres como elementos importantes del $\operatorname{caso}^{80}$.

No obstante, y a pesar de los avances conceptuales y jurisprudenciales comentados, el tribunal al analizar la obligación de investigar, juzgar y sancionar no explicó en qué consistía el deber de diligencia en el caso de violencia sexual, ni de qué manera el artículo 7.b de la Convención de Belém do Pará especifica y complementa las obligaciones emergentes de la Convención Americana. Tampoco la Corte analizó si dentro de los procesos emprendidos se estaban investigando puntualmente los hechos de violencia sexual que encontró como violatorios de las normas internacionales, ni cuáles serían los criterios para llevar a cabo una investigación con la debida diligencia frente a ellos. En materia de reparaciones, si bien la Corte otorgó una indemnización monetaria a las víctimas de violencia sexual ${ }^{81}$, al determinar las reparaciones inmateriales relativas a las investigaciones omitió establecer deberes particulares del Estado en la investigación de hechos de violencia sexual. Ni siquiera la Corte consideró que debía ordenar, dentro de la investigación general, el estudio particular de la conexión entre la violencia y el sexo de la víctima.

En definitiva, en los dos casos analizados, la Corte sostuvo que todas o algunas de las violaciones establecidas ocurrieron debido al origen étnico o al sexo de las víctimas. En Plan de Sánchez, la Corte consideró que la masacre ocurrió en un contexto de ataques indiscriminados contra la población maya y que ello tuvo un grave impacto negativo en este pueblo. En Castro Castro concluyó que algunas víctimas sufrieron violaciones de sus derechos exclusivamente por razón de su sexo y que, a su vez, fueron objeto de violencia sexual. Sin embargo, ello no acarreó ningún análisis acerca de la existencia de una obligación especial o adicional de investigación por parte del Estado en cuanto a la conexión entre violencia, discriminación y debida diligencia. Igualmente, a pesar de que la Corte dispuso reparaciones económicas diferenciadas por este tipo de violaciones, no lo hizo en cuanto a las investigaciones judiciales.

En el caso Moiwana, la Corte tomó en cuenta algunos factores que influyeron en la situación de impunidad que rodea a la masacre ocurrida en una aldea habitada por maroons en Suriname. En efecto, consideró expresamente que la ausencia de recursos efectivos es fuente de sufrimiento y angustia para las víctimas y sus familiares, y que la impunidad ha creado "en los miembros de la comunidad la convicción de que el Estado los discrimina activamente 82 ". La Corte enfatizó especialmente el efecto que la impunidad tiene en las tradiciones de los maroons y sostuvo que "los miembros de la comunidad (...) han sufrido la indignación y vergüenza de haber sido abandonados por el sistema de justicia penal de Suriname -a pesar de las graves acciones perpetradas en contra de su aldea- ${ }^{\prime 83}$. El tribunal reconoció que estas personas no sólo requieren justicia

\footnotetext{
78 Ibídem, párr. 379.

79 Ibídem, párr. 313.

80 La Comisión sí invocó la violencia contra las mujeres y la interpretación conjunta de las obligaciones de investigar y sancionar emergentes de los artículos 1, 8 y 25 de la Convención con el artículo 7 de la Convención de Belém do Pará, Ibídem, párr. 228, secciones p; q; r y párr. 369, sección f de sus alegatos finales.

81 Ibídem, párr. 433.c.ix y x.

82 Corte IDH, Caso de la Comunidad Moiwana v. Suriname, Sentencia del 15 de junio de 2005, Serie C № 124 , párr. 94.

83 Ibídem, párr. 96.
} 
sino también "conocer por qué ocurrieron las muertes"84. Pero estos reconocimientos expresos no llevaron a la Corte a exigir que la investigación determinara si hubo un motivo racial o étnico en la perpetración de la masacre, o si la correlativa denegación de justicia tuvo una motivación y/o efecto discriminatorio.

\section{Conclusión}

La Corte Interamericana ha sostenido con razón que el principio de protección igualitaria, efectiva, y no discriminatoria de la ley está consagrado en múltiples instrumentos internacionales. Y que este hecho es un reflejo de la existencia de un deber universal de respetar y garantizar los derechos humanos, emanado precisamente de aquel principio general y básico ${ }^{85}$. Pero estas dos verdades no relevan al intérprete de toda obligación de justificar sus apreciaciones y de realizar un análisis jurídico consistente de las consecuencias que se desprenden de tales verdades.

En particular, para órganos internacionales que derivan su legitimidad del poder de convicción de sus decisiones, resulta imperativo que expliquen de manera detallada y transparente sus determinaciones, las lógicas de sus razonamientos, los motivos para apartarse de textos expresos y las implicancias jurídicas que se derivan de la aplicación de distintos instrumentos jurídicos.

En este sentido, la Corte Interamericana de Derechos Humanos está en deuda con la comunidad hemisférica en dos sentidos. Por una parte, no ha explicado por qué puede apartarse del texto convencional para incluir nuevas categorías prohibidas de discriminación. Tampoco ha analizado o manifestado cuáles son las consecuencias de que una categoría esté expresamente incluida como prohibida y, en particular, si a ella se aplica un estándar de justificación más estricto en cada caso que se alegue una discriminación basada en ella.

A pesar de haber reconocido, en varias ocasiones, la relación intrínseca entre discriminación y estado de vulnerabilidad de diferentes grupos ${ }^{86}$, la Corte aún no ha desarrollado estándares particularizados relativos a las obligaciones de investigar, juzgar y sancionar las violaciones a los derechos de las personas pertenecientes a ellos, cuyos derechos son violados precisamente por dicha pertenencia. Si hay personas que por la discriminación tradicional sufrida se encuentran en una situación de particular desventaja frente al resto de la sociedad, la violencia de la que son víctimas no puede ser investigada con los mismos criterios y estándares que se utilizan frente a la de cualquier otro tipo. No sólo porque ello puede enmascarar que el origen de la violencia es precisamente un elemento discriminatorio, sino también porque no consideran las situaciones particulares de la víctima, tales como su género, su cultura, su lengua. Esto puede constituirse en un factor adicional de revictimización y, a la vez, puede llevar a una investigación ineficaz e inoperante.

Al igual que en muchos otros temas, como la conceptualización del fenómeno de las desapariciones forzadas ${ }^{87}$, el establecimiento de la incompatibilidad de las leyes de amnistía con la

84 Ibídem, párr. 97.

85 Corte IDH, OC 18, nota a pie de página № 33 correspondiente al párrafo 86, citando a 33 instrumentos internacionales de diversa naturaleza.

86 Corte IDH, OC 18, párr. 112 -trabajadores migratorios indocumentados-. Corte IDH, Caso Ximenes Lopes v. Brasil, Sentencia del 4 de julio de 2006, Serie C № 149, párr. 103-105 -personas que sufren discapacidades mentales-. Corte IDH, Caso Comunidad Indígena Sawhoyamaxa v. Paraguay, Sentencia del 29 de marzo de 2006, Serie C N 146, párr. 189 -pueblos indígenas-. Corte IDH, Caso de las Niñas Yean y Bosico v. República Dominicana, Sentencia del 8 de septiembre de 2005, Serie C No 130, párr. 134 -niñas y mujeres-.

$87 \mathrm{CIDH}$, Informe sobre la Situación de los Derechos Humanos en Argentina (1980), capítulo 3, El problema de los desaparecidos. 
Convención ${ }^{88}$ o la prohibición de la penalización del discurso ofensivo contra figuras públicas en casos de interés general ${ }^{89}$, la Comisión ha abierto caminos jurisprudenciales en materia de igualdad y no discriminación en el sistema interamericano. Tanto en la introducción de un análisis de escrutinio más estricto frente a categorías prohibidas de discriminación como en el desarrollo de la conexión entre violencia, discriminación y debida diligencia en la investigación. Quizás, en un tiempo no lejano, el tribunal interamericano siga estas líneas jurisprudenciales que otorgarán mayor protección a las víctimas de discriminación.

${ }^{88} \mathrm{CIDH}$, Informe $\mathrm{N}^{\circ}$ 28/92, Casos 10.174, 10.181, 10.240, 10.262, 10.309 y 10.311, del 2 de octubre de 1992, e Informe 29/92, en Informe Anual de la Comisión Interamericana de Derechos Humanos, 1992-1993.

$89 \mathrm{CIDH}$, Informe sobre la compatibilidad entre las leyes de desacato y la Convención Americana sobre Derechos Humanos, OEA/Ser. L/V/II.88, doc. 9 rev., 17 de febrero de 1995, 197-212. 